\title{
Comparison of two simple microaerobic atmospheres for cultivation of thermophilic campylobacters
}

\author{
T Popovic-Uroic, N Sterk-Kuzmanovic
}

\begin{abstract}
A comparison of a modification of the spirit burn method and one based on the Fortner principle was carried out on 3474 faecal samples from patients with diarrhoea. Of the 96 isolates of Campylobacter, 47 showed equal abundance of growth, regardless of the method used. By using the spirit burn method, however, growth of 33 isolates was significantly increased, and 18 out of those 33 isolates grew only in the spirit burn method atmosphere. The spirit burn method is more effective than the one based on the Fortner principle, it is easy to perform, quick, and cheap.
\end{abstract}

Optimal atmosphere for the growth of thermophilic campylobacters is between $5 \%$ and $10 \%$ oxygen and between $1 \%$ and $10 \%$ carbon dioxide. This may be produced in several ways. The evacuation-replacement system and gas generating envelopes are the method of choice. ${ }^{1}$ In many developing countries, however, resources do not allow these methods to be used and either a candle jar or a method based on the Fortner principle is used instead. ${ }^{2}$ Ribeiro et al first reported an improved version of the candle extinction jar in which methylated spirit is burnt instead of a candle. ${ }^{3}$ We report here a comparison of this method with one based on the Fortner principle.

Clinical Microbiology, University Hospital

for Infectious

Diseases, 41000

Zagreb, Mirogojska 8, Yugoslavia

T Popovic-Uroic

N Sterk-Kuzmanovic

Correspondence to: Dr T Popovic-Uroic

Accepted for publication

12 June 1991

\section{Methods}

We cultured a total of 3474 faecal samples from patients with diarrhoea. Each faecal specimen was plated in duplicate on Butzler's Virion medium. ${ }^{4}$ One plate was incubated in an atmosphere with the oxygen lowered by a method based on a modified Fortner's principle (MFP)

Semiquantitative analysis of campylobacter growth using the spirit burn method and the modified Fortner's principle

\begin{tabular}{llllll}
\hline \multicolumn{5}{c}{ Spirit burn method } & \\
\cline { 2 - 5 } & $\begin{array}{l}\text { Heavy } \\
\text { growth }\end{array}$ & $\begin{array}{l}>5 \\
\text { colonies }\end{array}$ & $\begin{array}{l}1-5 \\
\text { colonies }\end{array}$ & 0 & Total \\
\hline $\begin{array}{llllll}\text { Modified Fortner's principle } \\
+++ \\
++\end{array}$ & 36 & 9 & - & - & 45 \\
++ & 12 & 3 & 6 & - & 21 \\
0 & - & 3 & 8 & 1 & 12 \\
Total & $\mathbf{4 8}$ & 24 & 23 & -1 & 96 \\
\hline
\end{tabular}

in which culture plates are sealed in a plastic bag with another plate seeded with Escherichia coli. ${ }^{2}$ The other plate was placed in a jar where the oxygen was lowered by a modification of the spirit burn method. ${ }^{5}$ Briefly, $0.5 \mathrm{ml}$ of spirit is burnt in a $9 \mathrm{~cm}$ glass Petri dish, placed on the topmost culture plate a few seconds before replacing the lid of the $2.5 \mathrm{l}$ stainless steel jar. On cooling, a partial vacuum is formed that keeps the lid firmly in place, provided there is a proper seal.

After 48 hours of incubation at $42^{\circ} \mathrm{C}$ campylobacters were identified by morphology, Gram stain, positive catalase and oxidase reactions, susceptibility to nalidixic acid (30 $\mu \mathrm{g}$ discs) and resistance to cephalothin (30 $\mu \mathrm{g}$ discs). The distinction between $C$ jejuni and $C$ coli was determined by hippurate hydrolysis. ${ }^{6}$ Reference strains $C$ coli NCTC 11353 and $C$ jejuni NCTC 11168 were used as controls in the identification tests.

\section{Results}

Campylobacters were isolated from $96(2 \cdot 8 \%)$ of the 3474 specimens. Of these isolates, 50 were $C$ jejuni $(52 \%)$ and 46 were $C$ coli $(48 \%)$ (table). Of the 96 campylobacter isolates, 47 showed equal abundance of growth regardless of the method used (47 strains). By using the spirit burn method, however, the growth of 33 Campylobacter strains was significantly increased, and 18 out of those 33 isolates grew only in the spirit burn method atmosphere; only one strain failed to grow.

\section{Conclusion}

The atmosphere suitable for the growth of campylobacters can be obtained in several ways. The method of choice greatly depends on its relative cost. More sophisticated procedures, such as disposable gas generating envelopes and evacuation replacement techniques, are often not available in developing countries. Therefore, several simple, economical methods have been devised. Ribeiro et $a l^{3}$ have shown that incubation of campylobacters in a candle jar is inferior to incubation in an atmosphere produced by the spirit burn method. Furthermore, they observed that evacuation of a jar coupled with the provision of carbon dioxide was as efficient as the spirit burn method. In our study the spirit burn method was more reliable than that based on 
the Fortner principle. The method is very easy to perform and it is quick and cheap. It can be recommended for use in those laboratories where more costly supplies are limited.

We gratefully acknowledge the help of Dr M B Skirrow.

1 Bolton FJ, Coates D. A comparison of microaerobic systems for the culture of Campylobacter jejuni and Campylobacter coli. Eur J Clin Microbiol 1983;2:105-10.

2 Karmali MA, Fleming PC. Application of the Fortner principle to isolation of Campylobacter from stools. J Clin Microbiol 1989;10:245-7.
3 Ribeiro CD, Marks J, Grimshaw AD. Economic cultivation of "thermophilic" Campylobacter spp. J Clin Pathol 1985;38:1311-13.

4 Goossens H, DeBoeck M, Butzler JP. A new selective medium for the isolation of Campylobacter jejuni from human faeces. Eur J Clin Microbiol 1983;2:389-94.

5 Skirrow MB, Vickery CR, Benjamin J, Lovelock MR, Evans JJ. Cheap microaerobic atmospheres: modification of the methylated spirit burn method. In: Kaijser B, Falsen E, eds. Campylobacter IV: Proceedings of the fourth international workshop on Campylobacter infections. Goteborg: national workshop on Campylobacter in
University of Goteborg, 1988:79-80.

6 Morris GK, Patton CMP. Campylobacter. In: Lennette EH, Ballow's A, Hausler WJ Jr, Shadomy HJ, eds. Manual of clinical microbiology. Washington, DC.: American Society for Microbiology, 1985:302-8. 